American Journal of Pharmaceutical Education 2017; 81 (2) Article 37.

\title{
REVIEW
}

\section{A Review of Legal Decisions Relevant to Technical Standards Used in Pharmacy School Admissions}

\author{
Douglas A. Lipton, JD, BS Pharm \\ Winchester Medical Center, Winchester, Virginia \\ Submitted September 28, 2015; accepted January 16, 2016; published March 25, 2017.
}

\begin{abstract}
The implementation of an effective and legally sound technical standards procedure for pharmacy schools requires a proactive approach by admissions officers. Applicants with disabilities are accorded significant rights that must not be infringed during the admissions process in order to ensure compliance with applicable law. This article provides a review of applicable state cases, federal cases, and OCR decisions and guidance to help pharmacy schools identify procedures and implement technical standards into their admissions processes as required by ACPE Standards 2016.
\end{abstract}

Keywords: technical standards, admissions, disability, Office for Civil Rights, case law

\section{INTRODUCTION}

Pharmacy admissions departments should be aware that their use of technical standards in admissions must comply with the Americans with Disabilities Act, Section 504 of the Rehabilitation Act of 1973, the pertinent case law, and the guidance provided by the U.S. Department of Education Office for Civil Rights (OCR). Best practices for the use of technical standards in admissions can be gleaned from the holdings of the cases listed in Appendix 1.

In developing technical standards, pharmacy schools should use criteria that are: essential, ${ }^{1}$ based on accreditation standards, and possess a rational relationship to the program. ${ }^{2}$ Using a two-step admissions process that avoids pre-admission screening of applicants for disabilities and addresses the needs of each applicant individually on a case-by-case basis is strongly recommended. ${ }^{2}$ To accomplish this, schools should establish a panel or committee with the appropriate knowledge to handle requests for accommodations and gather sufficient medical documentation so that the applicant can be fairly evaluated. $^{2}$

The panel or committee should attempt to identify accommodations that will allow applicants to meet the technical standards ${ }^{2}$ and thoroughly evaluate the existence of auxiliary aids that may prevent the exclusion of any applicant with a disability. ${ }^{3}$ Lastly, programs must consider whether a required programmatic element is

Corresponding Author: Douglas A. Lipton, Bernard J. Dunn School of Pharmacy, 1775 North Sector Court, Shenandoah University, Winchester, VA 22601. Tel: 540-665-1281. E-mail: rphesq@gmail.com

Note: The author was employed at Shenandoah University at the time this manuscript was submitted for publication. truly essential and consider a series of alternatives to the element that may impede a person with a disability. ${ }^{4}$

Section 16.5 of the new ACPE Standards 2016 requires that admission materials include "technical standards for graduation." $"$ The use of technical standards in admissions has resulted in a substantial amount of litigation and the issuance of numerous letter rulings by the OCR.

The Office for Civil Rights (OCR) is the branch of the U.S. Department of Education that is responsible for enforcing federal civil rights laws that prohibit discrimination in educational programs that receive funding from the Department of Education. Because Department of Education funding includes funding grants to states for educational purposes and the federal guaranteeing of student loans, OCR is able to exert authority over every educational institution and every pharmacy program in the United States. The laws that are the subject of OCR's enforcement activities include: Title VI of the Civil Rights Act of 1964; Title IX of the Educational Amendments of 1972; Section 504 of the Rehabilitation Act of 1973; the Age Discrimination Act of 1975; and Title II (public entities) of the Americans with Disabilities Act of $1990 .^{6}$

The OCR's duties include the provision of technical assistance to educational institutions to help them comply with civil rights laws and the resolution of discrimination complaints that are filed against educational institutions. The rulings and case decisions that are issued by OCR in response to claims of discrimination provide educational institutions with valuable insights into what OCR considers to be discriminatory behavior and what steps institutions can take to avoid being found in violation of the OCR enforced civil rights laws. 


\section{American Journal of Pharmaceutical Education 2017; 81 (2) Article 37.}

This article will focus on two OCR enforced laws: Section 504 of the Rehabilitation Act of $1973^{7}$ (hereafter referred to as Section 504) and the Americans with Disabilities $\mathrm{Act}^{8}$ (ADA). Since Section 504 is directly tied to the receipt of federal funding, its application is universal. The ADA, on the other hand, has distinct requirements for entities that vary based upon whether the entity is public or private. The requirements that apply to public entities (eg, state and local governmental entities) are found in Title II $^{9}$ of the ADA and the requirements that apply to private entities are found in Title III ${ }^{10}$ of the ADA. Title III's requirements prohibit disability discrimination by private businesses that are open to the public and fall into an ADA listed category. State-supported pharmacy schools must meet the standards in Title II of the ADA, while private pharmacy schools must comply with Title III's requirements. The requirements of Title II are more stringent than those of Title III.

Another interesting facet of the trend in disability law was the passage of the ADA Amendments Act of 2008 (Amendments Act). The Amendments Act was passed to broaden the scope of applicability of the ADA and significantly expanded the definition of disability under both the ADA and Section 504. ${ }^{11}$ This trend of expanded protection for persons with disabilities has continued, and institutions should be aware that their requirements are likely to continue to evolve and expand.

This article will review the recent cases and OCR rulings to provide a framework to assist schools of pharmacy in developing their procedures for the use of technical standards in their admissions processes. A cursory review of the applicable laws and regulations is also provided as background information necessary for a proper understanding of the cases. Schools must be vigilant to ascertain that their use of technical standards in admissions does not violate either the ADA or Section 504 by unlawfully discriminating against persons with disabilities.

\section{NONDISCRIMINATION REQUIREMENTS UNDER SECTION 504 AND THE ADA Overview of Eligibility Criteria}

Section 504 prohibits colleges and universities that receive federal financial assistance from excluding otherwise qualified persons with disabilities from participation in their programs solely on the basis of the individuals' disabilities. ${ }^{12}$ Furthermore, the regulations implementing Section 504 specifically prohibit the use of criteria "that have the effect of subjecting qualified handicapped persons to discrimination on the basis of handicap."13

The Americans with Disabilities Act similarly prohibits "the imposition of eligibility criteria that screen out or tend to screen out an individual with a disability or any class of individuals with disabilities [...] unless such criteria can be shown to be necessary [...]." ${ }^{\text {14 }}$ Given these prohibitions, the improper use of technical standards in admissions can easily result in a violation of the ADA and/or Section 504's prohibition on the use of discriminatory eligibility criteria.

\section{Qualified Applicants and Students}

One of the keys to the appropriate use of technical standards is making sure that the standards do not exclude "qualified" individuals from participation in the program because of the individuals' disabilities. Section 504's regulations specify that a qualified individual is a person with a disability who is able to meet the academic and technical standards that are required for admission and participation in the program. ${ }^{15}$ As the cases will illustrate, any standards adopted that result in the exclusion of persons with disabilities will need to withstand an analysis of the link between the standards and success in the program.

\section{Reasonable Accommodations}

The ADA's definition of a "qualified individual with a disability" includes individuals with disabilities who are able to meet essential eligibility requirements with or without reasonable modifications [emphasis added]. ${ }^{16}$ Students with disabilities are entitled to request "reasonable accommodations" to enable them to meet a program's academic and technical standards and institutions are required to provide reasonable accommodations in response to these requests. ${ }^{17}$ Examples of reasonable modifications specifically noted in the regulations include: "changes in the length of time permitted for the completion of degree requirements, substitution of specific courses required for the completion of degree requirements, and adaptation of the manner in which specific courses are conducted." 18

Institutions must also provide "auxiliary aids" when necessary to prevent the exclusion of individuals from a program. A few examples of auxiliary aids include: note takers, computer-aided transcription services, written materials, assistive listening devices, telephones compatible with hearing aids, and videotext displays. ${ }^{19}$

Importantly, institutions are not required to make accommodations or provide auxiliary aids that would fundamentally alter the nature of the program or result in an undue burden on the institution. ${ }^{20}$ Many cases have hinged on whether requested accommodations would produce a fundamental change in the nature of the program.

\section{Pre-admission Screening of Applicants with Disabilities}

When pharmacy schools begin including their technical standards in their admissions materials as 


\section{American Journal of Pharmaceutical Education 2017; 81 (2) Article 37.}

required by Section 16.5 of ACPE Standards 2016, their admissions departments should expect to be contacted by applicants with disabilities who are concerned with their ability to meet the technical standards. However, Section 504 specifically prohibits pre-admission inquiries to determine whether an individual is handicapped. ${ }^{21}$ The only exception to this prohibition is when the institution is "taking remedial action to correct the effects of past discrimination." 22

The Office for Civil Rights addressed and tacitly approved a two-step admissions-disability inquiry process in its Letter to: University of Texas Medical Branch, ${ }^{2}$ which is covered in the cases section below. Admissions departments should note this prohibition and pay attention to the protocol used by the University of Texas Medical Branch.

\section{DECISIONS BY THE OFFICE FOR CIVIL RIGHTS}

\section{Case 1: Southeastern Community College v Frances B. Davis}

The first case wherein the US Supreme Court authorized the use of technical standards in admissions subsequent to passage of Section 504 was Southeastern Community College v Frances B. Davis (442 US 397, 99 SCt 2361 [June 11, 1979]). ${ }^{23}$ This was a seminal educational disability law case and the first one wherein the US Supreme Court addressed the issue of whether a clinical training program could require physical qualifications for admission without violating Section 504's prohibition on discrimination against handicapped persons. ${ }^{23}$ The plaintiff in this case, Frances B. Davis, sought to become a registered nurse and applied to the nursing program at Southeastern. ${ }^{24}$ During her interview with nursing faculty members, Davis exhibited difficulty with understanding questions and acknowledged a history of hearing problems. Davis was subsequently diagnosed with bilateral, sensorineural hearing loss. While it was determined that she would be able to hear almost as well as a person with normal hearing, she would still need to lip read for effective communication. Proper communication would require that speakers obtain her attention and look directly at her while speaking.

The nursing program determined that it would be impossible for Davis to safely participate "in the normal clinical training program" and that the necessary modifications would "prevent her from realizing the benefits of the program [...]." ${ }^{24}$ Southeastern consulted the executive director of the North Carolina Board of Nursing and subsequently denied Davis' application. Davis requested that Southeastern reconsider their decision. A meeting of the entire nursing staff was convened at which the staff voted to deny Davis admission. Davis then filed suit against Southeastern in Federal District Court, alleging a violation of Section 504 of the Rehabilitation Act, and the case was eventually appealed to the Supreme Court. ${ }^{24}$

The Supreme Court noted that the applicable regulations defined a qualified handicapped person as a handicapped person who meets the academic and technical standards required for admission to or participation in the applicable program. ${ }^{25}$ One of the regulatory explanatory notes also defined technical standards to mean "all nonacademic admissions criteria that are essential to participation in the program in question." 26

The Supreme Court ruled that handicapped persons could be required to meet technical standards and that the technical standards could include necessary physical qualifications. ${ }^{27}$ The Supreme Court defined "an otherwise qualified person as one who is able to meet all of the program's requirements in spite of his handicap." ${ }^{26}$ Davis also attempted to challenge the inclusion of the physical qualifications for the program and sought to only take the classes without the clinical components. The Supreme Court ruled that Davis' request would constitute a fundamental alteration in the nature of the program. ${ }^{28}$

\section{Case 2: Ohio Civil Rights Commission et al., v Case Western Reserve University}

A case where the use of accreditation standards in the development of technical standards was supported by a court is Ohio Civil Rights Commission et al., v Case Western Reserve University (76 Ohio St 3d 168 [1996]). This case was brought by a blind medical school applicant, Cheryl Fischer, who was denied admission to Case Western Reserve University's (CWRU's) medical school. ${ }^{28}$ This case was brought under an Ohio state law that prohibited discriminatory practices against persons with disabilities. ${ }^{29}$ As a case decided under state law, it does not have any binding precedential value outside of the state of Ohio. However, institutions should allow this case to serve as a reminder that they are subject to their own specific state and local laws, which may have even greater disability protections than those provided by federal law.

Following her graduation from CWRU, Fischer applied to CWRU's medical school. ${ }^{29}$ The CWRU medical school belonged to the Association of American Medical Colleges, which adopted a technical standards report in 1979. ${ }^{29}$ These technical standards required medical school candidates to have the ability "to observe demonstrations and experiments in the basic sciences" and "to observe patients accurately at a distance and close at hand." 29 The report also stated that: "a candidate should be able to perform in a reasonably independent manner. The use of a trained intermediary means that a candidate's 


\section{American Journal of Pharmaceutical Education 2017; 81 (2) Article 37.}

judgment must be mediated by someone else's power of selection and observation." 29

Although the use of these standards was not mandatory, AAMC encouraged their use and the CWRU medical school used them as a guideline to evaluate the four to five thousand applications it received on an annual basis. ${ }^{29}$ The medical school ultimately determined that Fischer would not be able to complete the program and that no accommodation would enable her to meet the course requirements. ${ }^{29}$ Some of the requirements that the medical school did not believe Fischer would be able to complete included: observing and identifying tissues and organ structures, starting an intravenous (IV) line, drawing blood, taking night call, reacting in emergencies, performing physical examinations, and reading electrocardiograms and x-rays. ${ }^{29}$

The Ohio Supreme Court defined an otherwise qualified handicapped person as one who could safely and substantially perform the educational program's essential requirements with reasonable accommodation. ${ }^{29}$ The court also noted than an accommodation was not reasonable if it required fundamental alterations in the essential nature of the program or imposed an undue financial or administrative burden. ${ }^{29}$

The accommodations requested by the Ohio Civil Rights Commission on Fischer's behalf included using intermediaries to read x-rays and patient charts and to perform parts of a physical examination as well as the waiver of course requirements to draw blood and start an IV. ${ }^{29}$ The Ohio Supreme Court held that the use of an intermediary and the waiver of the requested requirements would fundamentally alter the program and ruled in favor of the CWRU medical school.

\section{Case 3: Emily McCulley v University of Kansas School of Medicine}

A case where technical standards were required by a school's accrediting body is Emily McCulley $v$ University of Kansas School of Medicine (2014 US App LEXIS 21777 [ $10^{\text {th }}$ Cir Nov. 14, 2014]). This case concerned the rejection of Emily McCulley's application to the University of Kansas School of Medicine (UKSM) based on her inability to meet the school's technical standards. McCulley suffered from type III spinal muscular atrophy, which limited her arm strength and resulted in her needing to use a wheelchair. ${ }^{29}$

Upon her acceptance into the program, McCulley was given a form for her to use to describe any accommodations she would need. ${ }^{30}$ McCulley completed and returned the form, met with UKSM staff, and subsequently provided a more detailed request for accommodations. ${ }^{30}$ The UKSM reviewed her request and provided her with a list of the physical requirements necessary for completion of the program so that her physician could make specific accommodation recommendations. The requested accommodations included having a staff person to assist her with: the lifting and positioning of patients; the stabilization of elderly patients; and the performance of basic life support. ${ }^{30}$ The UKSM's clinical faculty reviewed the requested accommodations, and based on the recommendation of faculty members, the acting dean concluded that McCulley would not be able to meet the school's motor technical standard and rescinded her offer of admission. ${ }^{30}$

The issue in this case was whether the requested accommodations would require UKSM to make fundamental alterations to the nature of its program. ${ }^{30}$ A very important fact for consideration in the court's analysis was that UKSM was required to articulate technical standards for all admitted students to meet as part of its accreditation. ${ }^{30}$ Also, the motor technical standard adopted by UKSM mandated that students "'be physically able to. .. carryout diagnostic procedures' and 'provide general care and emergency treatment to patients,' including CPR, opening obstructed airways, and 'obstetrical maneuvers." "30

The school argued that having a surrogate perform the requested accommodations for McCulley would render her an observer, and that having others interacting with patients on her behalf would fundamentally alter the nature of the program, which trains physicians to interact with patients including in emergency situations when assistance is not available. ${ }^{30}$

The court ruled that the requested accommodations would require UKSM to change its motor technical standard, which is related to its accreditation, and that such a change would constitute a fundamental alteration to the nature of its program. ${ }^{30}$ Because the McCulley case was tried in federal court and appealed to the $10^{\text {th }}$ Circuit Court of Appeals, the ruling in this case is binding precedent for all states in the $10^{\text {th }}$ Circuit (Colorado, Kansas, New Mexico, Oklahoma, Utah, and Wyoming) and can be used as persuasive authority in all US courts.

\section{Case 4: Letter to: University of Texas Medical Branch}

A case wherein OCR acknowledged and tacitly endorsed the majority of the best practices proposed in this review is Letter to: University of Texas Medical Branch (06-04-2067; 2005 NDLR (LRP) LEXIS 253; 30 NDLR 154 [March 21, 2005]). The guidance provided in the OCR decision letter sets out an admissions technical standards framework that all schools should consider implementing. This OCR decision letter addressed an allegation that the University of Texas Medical Branch (UTMB) 


\section{American Journal of Pharmaceutical Education 2017; 81 (2) Article 37.}

unlawfully discriminated against a medical school applicant (complainant) based on her "dystonia" disability in violation of Section 504 of the Rehabilitation Act. $^{2}$

The complainant was conditionally accepted to UTMB based on her academic qualifications and a successful interview. ${ }^{2}$ The UTMB's admissions process included having applicants complete a technical standards certification form regarding their ability to perform the essential functions of the curriculum after a determination of academic qualification. ${ }^{2}$ The issue presented in this case was whether the complainant was capable of meeting the technical standards required for admission and participation in the program. ${ }^{2}$

The UTMB provided the OCR with documentation showing that its technical standards were created and modeled after those made available by the American Association of Medical Colleges. The UTMB also used these standards to create an essential function statement that they used to determine whether applicants met the standards for admission and participation in the program. ${ }^{2}$ The UTMB's "statement of abilities and attributes" reflected the critical activities students must be capable of performing in order to complete a generalist medical school curriculum, including necessary psychomotor skills. $^{2}$

These requirements included: having motor functions sufficient to obtain data from patients using tactile, auditory, and visual maneuvers; possessing the requisite strength, mobility, and dexterity to obtain important information and perform procedures reasonably required to care of patients; and having the motor skills required to administer general care and emergency treatment to patients as reasonably required. ${ }^{2}$ Some examples of the activities that medical students were required to be able to complete included: perform CPR, don protective clothing, manually ventilate a patient, and obtain vital signs. ${ }^{2}$

The UTMB also had in place a process for making decisions regarding the need for accommodations through the use of its ADA panel, which consisted of the ADA coordinator, student ADA liaison, and coordinator of services for students with disabilities. ${ }^{2}$ This panel was responsible for reviewing documentation and ensuring that applicants were assessed using acceptable means by qualified professionals. ${ }^{2}$ The panel's procedures also called for case-by-case evaluation of applicants with disabilities and required that students possess the academic, physical, and emotional capabilities necessary to complete the full curriculum and achieve the level of competence required. ${ }^{2}$

However, when the complainant provided the dean with a letter indicating that she had poor coordination of her right arm, a limited range of motion, difficulty completing fine motor tasks with both hands, could not participate in surgery, treating trauma, delivering new life, or performing certain procedures for fear of compromising patient's well-being, the dean rescinded her offer of conditional admission. ${ }^{2}$

The dean's rescission did not follow UTMB's established policies and UTMB had the dean reinstate the complainant's conditional acceptance. The ADA panel was then convened to assess the complainant's ability to complete the program. ${ }^{2}$ The panel reviewed the information provided by the complainant, which included a letter from her physician stating that neither hand of the complainant could be considered useful for much other than gross motor movements. ${ }^{2}$ The complainant's request for accommodations also included the provision of a physician assistant to perform tasks. ${ }^{2}$

The panel decided that the complainant could not complete the curriculum due to physical limitations and that her accommodation request for a third party to perform tasks that were elements of the curriculum would fundamentally alter the nature of required courses and would fundamentally alter the nature of the educational experience. ${ }^{2}$ The panel also considered other options and determined that no reasonable accommodation could address the limitations that the complainant's physician had identified. ${ }^{2}$

The Office for Civil Rights reviewed the discrimination complaint and concluded that the complainant was not a qualified person with a disability because she was unable to meet the technical standards requisite for participation in the program. The OCR noted that the technical standards required that the applicant have psychomotor skills sufficient to perform essential tasks and that the evidence indicated a rational relationship between the technical standards and the UTMB program of study. ${ }^{2}$ The decision letter went on to state that the determination was based on the assessment of professionals with appropriate credentials who had applied appropriate criteria. The OCR also noted that UTMB was unable to identify any accommodations that would have allowed the complainant to perform the essential curricular tasks of physical examinations and clinical procedures that required the use of her hands. ${ }^{2}$

While OCR rulings do not have the same binding precedential effect as court case decisions, OCR decision letters are tremendously valuable because they provide analysis and direction directly from the administrative agency that is charged with enforcing the antidiscrimination disability laws. Pharmacy schools should use the guidance provided in OCR decision letters to craft antidiscrimination policies. 


\section{American Journal of Pharmaceutical Education 2017; 81 (2) Article 37.}

\section{Case 5: Letter to: Appalachian State University}

A case that highlights how important it is for schools to consider alternatives and whether academic requirements are truly essential is Letter to: Appalachian State University (11-052085; 2006 NDLR (LRP) LEXIS 578; 34 NDLR 176 [August 18, 2006]). This OCR decision did not specifically address the use of technical standards in admissions but provides valuable insight into how OCR analyzes an institution's process of determining whether a requirement is educationally and rationally justifiable. ${ }^{5}$ The complainant in this case was a music therapy major at Appalachian State University (ASU) who had severe bilateral hearing loss and was profoundly hearing impaired. ${ }^{5}$ She had difficulty singing on key in a pleasant voice with appropriate volume, and this presented problems in her coursework. ${ }^{5}$

Among the numerous allegations made by the complainant in this case was that she was treated differently from nondisabled students because she was told she could not earn a music therapy degree because she was unable to match pitch $100 \%$ of the time when other students without hearing impairments were permitted to earn a music therapy degree without being required to match pitch $100 \%$ of the time. ${ }^{5}$ The OCR reviewed the ASU's actions to see if it complied with Section 504's requirement that institutions make modifications to their academic requirements to ensure that the requirements do not discriminate or have the effect of discriminating against qualified students with disabilities unless such requirements are essential to the course of instruction. ${ }^{5}$

The letter noted that the "[c]ourts and OCR generally defer to academic determinations by colleges and universities based on the expertise of the institution and the right to academic freedom, as long as the institution can show that it reached the determination through a reasoned and informed process." ${ }^{5}$ Determinations of the requirements to graduate with a specific degree are academic determinations that are entitled to more deference than decisions regarding the modifications or academic adjustments the student needs to complete program requirements. ${ }^{5}$

When reviewing the process that an institution used to determine whether an academic requirement is an essential element, the OCR considers whether the process included the following elements:

1. The decision is made by a group of people who are trained, knowledgeable and experienced in the area;

2. Decision-makers consider a series of alternatives as essential requirements; and

3. The decision follows a careful, thoughtful and rational review of the academic program and its requirements. $^{5}$
The OCR went on to note that the requirements for programs that lead to licensure in a profession are often directly related to the performance of the duties of that profession, but that "[d]ifferent institutions may develop different essential requirements for their programs." ASU's defense for the inclusion of the ability to sing on key as a graduation requirement was based on the Professional Competencies of the American Music Therapy Association (AMTA), but ASU was unable to provide OCR with any evidence that it had convened a knowledgeable group of people to consider a series of alternatives to the essential requirements or otherwise conducted the type of process containing the three elements preferred by OCR as set forth above. ${ }^{5}$ The ASU's program director was also unable to explain to OCR how the AMTA determined what was essential to earning a degree in music therapy. ${ }^{5}$

In order to address OCR's concerns with ASU's process for determining the essential requirements for earning a music therapy degree, the ASU and OCR entered into a commitment to resolve that required ASU to use a process including the three elements set forth in the decision letter to determine which requirements are essential to earning a music therapy degree and therefore not subject to modification. ${ }^{5}$ Lastly, OCR recommended that ASU provide clear notice of its requirements to prevent misunderstandings regarding the program's expectations. ${ }^{5}$

\section{ADAPTIVE TECHNOLOGY}

No review of the use of technical standards would be complete without a brief discussion of how advances in technology may impact and enable persons with disabilities to meet academic and technical standards that were previously beyond their reach. In its ruling in Southeastern Community College v Davis, the US Supreme Court foresaw that technological advances could be expected to blur the lines between previously lawful refusals to extend accommodations and illegal discrimination against handicapped persons. ${ }^{26}$ The court noted that an insistence on continuing past requirements and practices could arbitrarily deprive genuinely qualified handicapped persons of opportunities to participate as technological advances enhanced the opportunities that are available for them. ${ }^{20}$ Thus, a refusal to modify an existing program in response to technological advances could become unreasonable and discriminatory. ${ }^{24}$

\section{Case 6: Featherstone v. Pacific Northwest University of Health Sciences}

A recent case that illustrates the importance of considering technological advances when determining whether students are otherwise qualified is Featherstone v. Pacific 


\section{American Journal of Pharmaceutical Education 2017; 81 (2) Article 37.}

Northwest University of Health Sciences (No. 1:CV-143084-SMJ [E.D. Wash. 2014]). In this case, Zachary Featherstone, who was deaf and unable to lip-read in educational settings, was initially accepted into the osteopathic medicine program at Pacific Northwest University (PNWU). ${ }^{30}$ The university then requested that Featherstone postpone matriculation for a year to allow it to obtain disability services to assist him. Featherstone agreed to the postponement and PNWU subsequently withdrew Featherstone's application, citing concerns for patient safety in clinical settings, compromised educational experiences for Featherstone's classmates, and the university's anticipation that Featherstone would be unable to meet time requirements during performance examinations. $^{31}$

Featherstone responded by filing suit in Federal District Court where he sought to obtain a preliminary injunction to require PNWU to allow him to matriculate with his class. Featherstone's suit included allegations that PNWU violated Title III of the ADA, Section 504 of the Rehabilitation Act, Washington's Law Against Discrimination, and nondiscrimination-based claims of breach of contract and promissory estoppel. ${ }^{31}$

The accommodations that Featherstone had requested of PNWU included interpreters for clinical settings and captioning services for classroom environments. ${ }^{31}$ While there is certainly a cost associated with the provision of such services, the regulations implementing Title III of the ADA specifically prohibit a person with a disability from being excluded because of the absence of auxiliary aids and services. Examples of the auxiliary aids and services set forth in the regulation include both "qualified interpreters" and numerous types of captioning services. ${ }^{31}$ The Federal District Court noted that it was quite common for these services to be provided in educational environments and that Featherstone could produce evidence that he was otherwise qualified with reasonable accommodations. $^{31}$

Once Featherstone met his burden of showing that he was otherwise qualified with reasonable accommodations, PNWU attempted to argue that the accommodations would require a fundamental alteration in their program, be cost prohibitive, and risk patient safety. The Federal District Court determined that the provision of an interpreter would only amount to a communication aid and that since Featherstone would still have to complete laboratory sessions, communicate with patients (through an interpreter), and finish the clinical portions of the program, the provision of an interpreter would not fundamentally alter the program. The court also found PNWU's claim of limited resources was unsubstantiated as sworn declarations were submitted indicating that interpreting services could be available by the beginning of the school term. ${ }^{31}$

Lastly, the Federal District Court noted that any facility where Featherstone might need to treat a patient would also be required to have sign language interpreting available for patients who might need the service, thereby attenuating the risk of patient harm due to Featherstone's disability. The court ruled that PNWU failed to establish that it was likely to succeed in proving that the provision of an interpreter and closed captioning would fundamentally alter the educational environment or impose an undue burden on PNWU and ordered PNWU to "immediately re-enroll Featherstone into its 2014-15 class at the College of Osteopathic Medicine." ${ }^{\prime 31}$

The decision in Featherstone is starkly different from the one reached by the US Supreme Court in the 1979 case involving Southeastern Community College and demonstrates how the law changes along with societal norms, resources, and technology. The case law is surprisingly sparse and few cases address the issue of the provision of technology in the educational setting. This may be attributable to institutions' compliance with the regulations and to the early involvement of informed disability attorneys who promptly negotiate resolutions in these matters without the need for court intervention. Either way, schools of pharmacy must make themselves aware of the current technology available when making determinations concerning an applicant's ability to meet technical standards. Because the Featherstone case was a US District Court case, any precedential value it has is limited to the Eastern District of Washington State and would not be binding even on that court. However, the opinion is well based in existing law and should be persuasive to other courts addressing this issue.

\section{CONCLUSION}

The legally appropriate development, use, and application of technical standards in pharmacy admissions are complex and essential. Technical standards are required by the ACPE Standards 2016 and are necessary to ensure that pharmacy students are able to succeed in their pharmacy programs and fulfill the essential functions of pharmacists upon graduation. The pharmacy profession is also uniquely demanding of its members. Pharmacists are required to be detail oriented, gifted in science and mathematics, empathetic, strong communicators, leaders, team members, and problem solvers. In addition to the requisite intellectual and mental attributes, pharmacists also frequently need to stand for long periods of time, possess the dexterity necessary to compound medications and set up IVs, and have the visual acuity to identify medication imprints and impurities. 


\section{American Journal of Pharmaceutical Education 2017; 81 (2) Article 37.}

Thus, pharmacy school admissions departments must exercise care in handling applicants to make sure they are fairly evaluated and treated as individuals throughout the admissions process. There is no substitute for the prior implementation of appropriate technical standards, resources, and processes to ensure that applicants with disabilities are accorded all of their rights under the disability laws. The cases and OCR guidance reviewed herein, summarized in the table of cases below, and set forth in the best practices presented at the beginning of this article should provide admissions departments with the information necessary to build or improve their technical standards admissions processes. While following this guidance will not necessarily make schools litigation or complaint proof, it can assist in the development of a legally sound and justifiable framework for the use of technical standards in admissions. Finally, pharmacy admissions departments should remember to proactively pursue routes of success for individuals with disabilities while keeping in mind that technology allows everyone, including those with disabilities, to do more than ever before.

\section{REFERENCES}

1. 42 USC \$12182(b)(2)(A)(i); 34 CFR §104.4B(VII)(4)(i).

2. 34 CFR 104.42(b)(4). Emily McCulley v University of Kansas

School of Medicine, 2014 US App. LEXIS 21777 (10th Cir. Nov. 14, 2014); Letter to: University of Texas Medical Branch, 06-04-2067;

2005 NDLR (LRP) LEXIS 253; 30 NDLR 154(2005).

3. 42 USC 12182(b)(2)(A) (i), 34 CFR 104.44 (a).

4. Letter to: Appalachian State University, 11-052085; 2006 NDLR (LRP) LEXIS 578; 34 NDLR 176 (August 18, 2006).

5. Accreditation Council for Pharmacy Education. Accreditation standards and key elements for the professional program in

pharmacy leading to the doctor of pharmacy degree. Standards 2016.
https://www.acpe-accredit.org/pdf/Standards2016FINAL.pdf. Accessed August 17, 2015.

6. About OCR. http://www2.ed.gov/about/offices/list/ocr/aboutocr. html. Accessed November 29, 2015.

7. 29 USC $\$ 791$ et seq.

8. 42 USC $\S 12131$ et seq. (Title II) and 42 USC $\S 12181$ et seq. (Title III).

9. State and Local Governments (Title II). http://www.ada.gov/ ada_title_II.htm. Accessed November 29, 2015.

10. Public Accommodations and Commercial Facilities (Title III). http://www.ada.gov/ada_title_III.htm. Accessed November 29, 2015. 11. Disability Discrimination. http://www2.ed.gov/policy/rights/ guid/ocr/disability.html. Accessed November 29, 2015.

12. 29 USC $\$ 794$.

13. 34 CFR $\S 104.4 \mathrm{~B}(\mathrm{VII})(4)(\mathrm{i})$.

14. 42 USC $\S 12182(b)(2)(A)(i)$.

15. 34 CFR $\S 104.3(1)(3)$.

16. 42 USC $\$ 12131(2), 28$ CFR $\$ 35.104$

17. 42 USC $\S 12182(b)(2)(A)(i) ; 34$ CFR $\S 104.44$ (a).

18. 34 CFR $\S 104.44(a)$.

19. 28 CFR $\$ 36.303$.

20. 28 CFR $\S 36.302,42$ USC $\S 12182(b)(2)(A)(i i i)$.

21. 34 CFR $\$ 104.42(b)(4)$.

22. 34 CFR $\S 104.42(b)(4) ; 34$ CFR $\$ 104.42(c)$.

23. Southeastern Community College v Frances B. Davis, 442 US 397, 99 SCt 2361 (June 11, 1979).

24. Southeastern Community College, 442 US at 402.

25. Southeastern Community College, 442 US at 406; citing 45 CFR $\S 84.3(\mathrm{k})(3)(1978)$.

26. Southeastern Community College, 442 US at 406; citing 45 CFR pt.84, App. A, p405 (1978).

27. Southeastern Community College, 442 US at 407, 409-10.

28. Ohio Civil Rights Commission, et al v Case Western Reserve University, 76 Ohio St 3d 168 (1996).

29. Emily McCulley v University of Kansas School of Medicine, 2014 US App. LEXIS 21777 (10th Cir. Nov. 14, 2014).

30. Featherstone v Pacific Northwest University of Health Sciences, No. 1:CV-14-3084-SMJ (E.D. Wash. 2014).

31. 28 CFR 36.303(b)(1). 


\section{American Journal of Pharmaceutical Education 2017; 81 (2) Article 37.}

Appendix 1. Case Holdings

Case: Southeastern Community College v Frances Davis ${ }^{24}$

Court: US Supreme Court

Date: June 11, 1979

Holding: Students must be able to meet technical and physical standards in spite of their handicaps.

Comment: The passage of the ADA Amendments and the increase in adaptive technology have decreased the precedential value of this case. If a similar case were brought today, the Court would likely order the school to provide the student with an interpreter and any appropriate adaptive technology.

Case: Ohio Civil Rights Commission et al., $v$ Case Western Reserve University ${ }^{29}$

Court: Ohio State Supreme Court

Date: July 31, 1996

Holding: The use of an intermediary and waiver of required elements that were related to accreditation standards would result in a fundamental alteration in the program.

Comment: It is important to distinguish the use of an intermediary for communication purposes as opposed to for purposes of actually meeting programmatic requirements.

Case: Emily McCulley v University of Kansas School of Medicine $e^{30}$

Court: US $10^{\text {th }}$ Circuit Court of Appeals

Date: November 14, 2014

Holding: Students must be able to meet motor technical standards that are related to accreditation and requiring a change would constitute a fundamental alteration of the program.

Comment: This case further illustrates that students need to be able to meet requisite standards with reasonable accommodations. The inability of the prospective student to perform basic life support measures for obstructed airways, obstetrics, and CPR resulted in a verdict for the school. It is possible that advances in technology may eventually allow a person with McCulley's disabilities to perform these acts in the future, which would result in a different outcome.

Case: Letter to: University of Texas Medical Branch ${ }^{2}$

Agency: Department of Education Office of Civil Rights

Date: March 21, 2005

Holding: Applicants must be capable of performing essential tasks that are rationally related to the program of study.

Comment: This case indicated OCR's approval of a two-step process for the use of technical standards in admission that should be standard policy for all schools.

Case: Letter to: Appalachian State University ${ }^{5}$

Agency: Department of Education Office of Civil Rights

Date: August 18, 2006

Holding: Institutions must consider alternatives to their academic requirements and make sure that their requirements are educationally and rationally justifiable.

Comment: In this case, OCR sets out a three-step process that institutions should use to determine if an academic requirement is essential. Institutions should consider adopting this process and make special note of the fact that different schools adopt different methods to ensure that students can perform essential functions. Institutions must consider alternatives.

Case: Featherstone v Pacific Northwest University of Health Sciences ${ }^{31}$

Court: US District Court for the Eastern District of Washington State

Date: July 22, 2014

Holding: The provision of a sign language interpreter and closed captioning were required as reasonable accommodations under the ADA and Section 504.

Comment: Featherstone indicates a huge shift from the Supreme Court's original ruling in Southeastern Community College and highlights the obligation of institutions to review and provide adaptive technology. Featherstone was likely made possible by the ADA's expansion of the protections accorded to people with disabilities and institutions must incorporate a review of the availability of auxiliary aids into their individualized assessments of applicants with disabilities. 